\title{
Quality of Working Life of cancer survivors: associations with health- and work-related variables
}

\author{
Merel de Jong $^{1} \cdot$ Sietske J. Tamminga ${ }^{1}$ - Monique H.W. Frings-Dresen ${ }^{1}$. \\ Angela G.E.M. de Boer ${ }^{1}$
}

Received: 21 July 2016 / Accepted: 4 December 2016 /Published online: 26 December 2016

(C) The Author(s) 2016. This article is published with open access at Springerlink.com

\begin{abstract}
Purpose This study aimed to (1) describe the Quality of Working Life (QWL) of cancer survivors and (2) explore associations between the QWL of cancer survivors and healthand work-related variables.

Methods Employed and self-employed cancer survivors were recruited through hospitals and patient organizations. They completed the Quality of Working Life Questionnaire for Cancer Survivors (QWLQ-CS) and health- and work-related variables in this cross-sectional study. The QWL scores of cancer survivors were described, and associations between QWL and health- and work-related variables were assessed.

Results The QWLQ-CS was completed by 302 cancer survivors ( $28 \%$ male) with a mean age of $52 \pm 8$ years. They were diagnosed between 0 and 10 years ago with various types of cancer, such as breast cancers, gastrointestinal cancers, urological cancers, and haematological cancers. The QWL mean score of cancer survivors was $75 \pm 12(0-100)$. Cancer survivors had statistically significant lower QWL scores when they had been treated with chemotherapy or when they reported comorbidity $(p \leq 0.05)$. Cancer survivors without managerial positions, with low incomes or physically demanding work, and who worked a proportion of their contract hours had statistically significantly lower QWL scores $(p \leq 0.05)$.

Conclusions This study described the QWL of cancer survivors and associations between QWL and health- and workrelated variables. Based on these variables, it is possible to
\end{abstract}

Angela G.E.M. de Boer

a.g.deboer@amc.uva.nl

1 Coronel Institute of Occupational Health, Academic Medical Center, University of Amsterdam, P.O. box 22660, 1100 DD Amsterdam, the Netherlands indicate groups of cancer survivors who need more attention and support regarding QWL and work continuation.

Keywords Quality of Working Life · Cancer survivors · Return-to-work · Work continuation · Patient reported outcomes $\cdot$ Cancer survivorship

\section{Introduction}

The rising incidence and prevalence of cancer worldwide [1] is affecting a large proportion of people of working age [2]. In 2016, it was estimated that 8.1 million US cancer survivors were between 15 and 69 years of age [3]. Some types of cancer, such as testicular cancer, tend to affect younger people, but many other cancer diagnoses are more common among older people (e.g., colorectal cancer) [3]. Next to younger people who survive cancer and are employed, cancer survivors of older age also return to work and continue to be part of the working population, as the retirement age rises in many countries [4]. Continuing employment is a positive outcome since for most cancer survivors, work helps with regaining a sense of normality [5] and provides personal satisfaction [6], and work satisfaction is associated with health-related quality of life [7].

Unfortunately, cancer survivors have a higher risk of unemployment than healthy controls [8]. For instance, older, fatigued, and lower-educated thyroid cancer survivors were found to be potentially at risk of having no employment [9]. A systematic literature review found that male cancer survivors are associated with a greater likelihood of being employed, and females with barriers related to returning to work and job loss [10]. Furthermore, health-related factors that are associated with a greater risk of unemployment or job loss include extensive 
surgery and advanced tumour stage [11]. The workrelated factor "physical workload," such as heavy lifting, has also been found to affect the employment of cancer survivors negatively [12]. On the positive side, workrelated factors such as workplace accommodations are positively associated with work continuation [13]. Quality of Working Life is also believed to be related to work continuation; the level of Quality of Working Life in nurses is a predictor of their intention to leave their job and organization [14], and a higher appreciation at work results in fewer older workers opting for early stage retirement [15].

To evaluate and improve work participation among cancer survivors, researchers have developed multiple interventions [16]. However, when evaluating the effectiveness of these person-centred interventions, it was found that the primary outcome measures are often return-towork rates or sick leave duration [17]. These measures do not indicate whether the intervention was successful in terms of the well-being and work satisfaction of cancer survivors. Therefore, it has been suggested that research should focus on the "work-related goals" that cancer survivors consider to be important, rather than on return-towork alone [18].

We know little about the Quality of Working Life (QWL) of cancer survivors. However, examining the experiences and perceptions about work life quality would make a valuable contribution to the existing literature on cancer survivors in employment. We know from previous research that cancer survivors with specific health- and work-related variables are higher at risk of unemployment. By exploring the relationship between QWL and health- and work-related variables, we might identify groups of cancer survivors based on these variables who potentially experience low QWL. These outcomes could be used to develop tailored interventions that aim to improve the return-to-work or work continuation processes of cancer survivors. This study therefore has two aims: (1) to describe the QWL of cancer survivors and (2) to explore associations between the QWL of cancer survivors and health- and work-related variables.

\section{Method}

\section{Design}

This study used a cross-sectional design. For transparent reporting of the outcomes, we used the checklist for STrengthening the Reporting of OBservational studies in Epidemiology (STROBE statement) [19]. Ethical approval was deemed unnecessary by the Medical Ethics Committee of the Academic Medical Center (W14_218\#14.17.0264).

\section{Participants}

The sample consisted of cancer survivors. Inclusion criteria were as follows: (1) a cancer diagnosis, (2) a cancer diagnosis made within the last 3 months to 10 years, (3) aged 18 to 65 , (4) employed of self-employed, having performed work activities in the last 4 weeks, and (5) fluent in Dutch. Exclusion criteria were as follows: (1) cancer diagnosis before the age of 18 , (2) having a psychiatric disorder, and (3) palliative treatment.

Various recruitment strategies were used (Fig. 1). Cancer specialists (i.e., oncologist) approached cancer survivors during an appointment or by post. Different departments in four hospitals in the Netherlands participated. Furthermore, a Dutch online cancer platform sent an email invitation to participate in the study to a panel of cancer survivors, and a patient organization for head and neck oncology placed the study invitation on its social media site. Furthermore, 12 cancer survivors who had been recruited in a hospital setting in a previous study received new invitations, as they had given their permission to be contacted for follow-up research.

The recruited cancer survivors were sent study information and a form that gave the researchers permission to contact cancer survivors by phone. During this phone call, cancer survivors could ask questions about the study and indicate whether they wished to participate. If so, they received an informed consent form by post. The informed consent form had to be signed and returned to the researchers.

\section{Procedure}

Between May 2015 and December 2015, cancer survivors completed a self-administered questionnaire comprising a QWL questionnaire, demographics, and health- and workrelated variables. The questionnaire was available in a paper or digital version. For the digital version, we used the online survey software Fluidsurveys (SurveyMonkey Europe, Ireland 2014).

\section{Measurements}

Demographic data were obtained (i.e., gender, age, marital status, breadwinner position, ethnicity, and level of education).

$Q W L$

QWL was assessed with the Quality of Working Life Questionnaire (QWLQ-CS) for cancer survivors [20]. This questionnaire was developed in Dutch specifically for cancer survivors who are employed within an organization or selfemployed. In this study, we collected data with the use of the preliminary version of the QWLQ-CS with 104 items [21]. 
Fig. 1 Flow chart of recruitment of cancer survivors

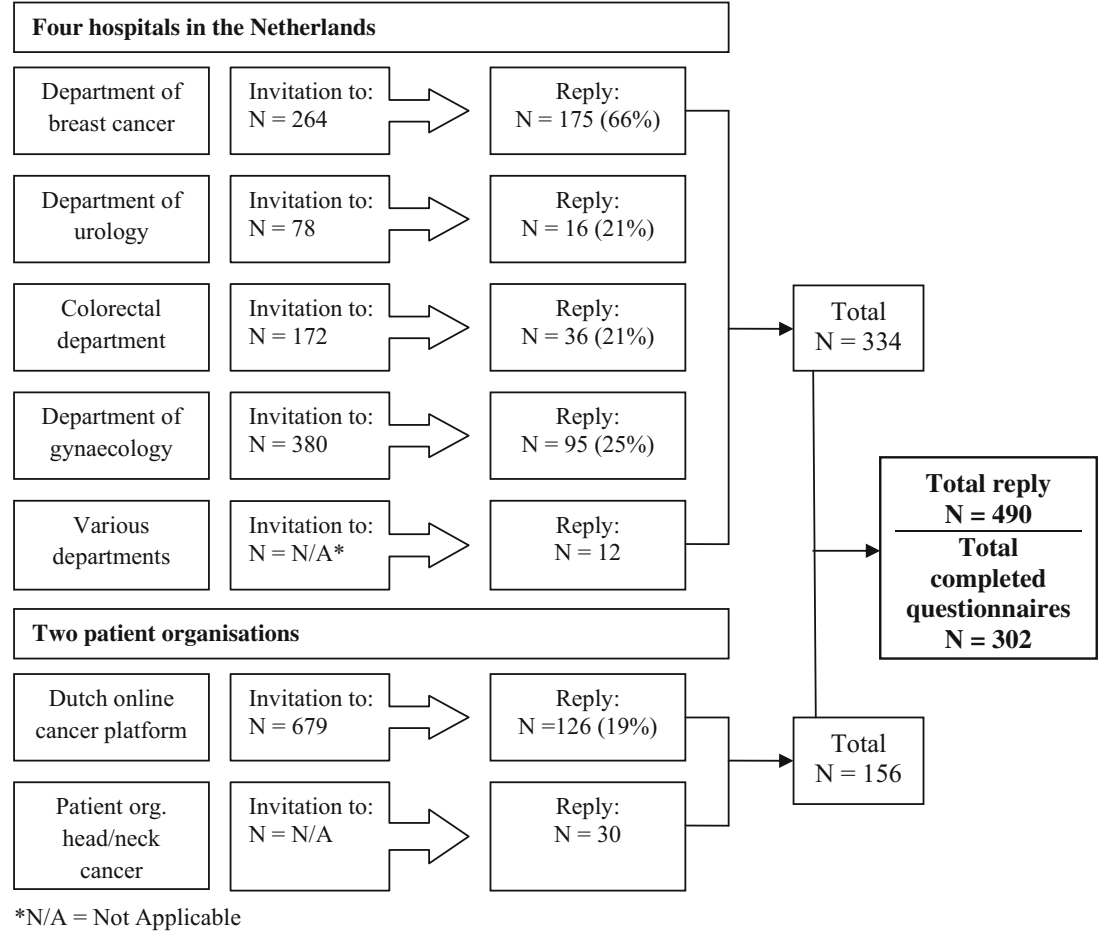

Later on, we developed the final 23-item QWLQ-CS which proved to be reliable and valid for use at group level (de Jong et al., submitted for publication). The outcomes on the items of the final version of the QWLQ-CS were analysed to describe the QWL of cancer survivors in this study. The final version consisted of 23 items divided into five subscales: (1) meaning of work, (2) perception of the work situation, (3) atmosphere in the work environment, (4) understanding and recognition in the organization, and (5) problems due to the health situation (de Jong et al., submitted for publication). The response categories ranged on a 6-point Likert scale from "Totally disagree" to "Totally agree." For self-employed cancer survivors, an extra response category "Not applicable" was added to six items, for instance to the item about support from colleagues. The internal consistency of the QWLQ-CS (Cronbach's alpha $=0.91$ ) and subscales was good (Cronbach's alpha $=0.83-0.86$ ). Cancer survivors had to complete $50 \%$ of the subscale or total QWLQ-CS to calculate the score. Scores on negative items must be reversed $(N=5)$, and responses in the "Not applicable" category were scored as missing. A higher score corresponded to a higher QWL (range $0-100)$.

\section{Health-related variables}

After cancer survivors completed the QWLQ-CS, they were asked seven items relating to their health situation. These items were constructed into one health-related questionnaire. The content of the items was as follows: (1) number and type of cancer diagnosis, (2) date of most recent cancer diagnosis,
(3) type of cancer treatment, (4) being currently treated, and if not, how long ago did cancer survivors received their last treatment, and (5) co-morbidity. All response scales were categorical. Co-morbidity was assessed by the following item: "Are you limited in your work by other physical diseases?" (yes/no).

\section{Work-related variables}

The following questionnaire contained seven work-related items: (1) type of work sector in which cancer survivors were currently employed, (2) in a managerial position (yes/no), (3) number of years in the job, (4) type of employment contract, (5) currently working total or a proportion of contract hours, (6) number of contract hours, and (7) gross income. All response scales were categorical. For instance, type of work sector included all possible sectors in the Netherlands such as healthcare, technology, and facility management. Furthermore, this work-related questionnaire comprised two subscales of the Dutch: "Questionnaire Perception and Judgement of Work" (VBBA) [22] which assessed physically and mentally demanding work. Both subscales contained seven items on a 4-point Likert scale (Never-Always) with a higher score corresponding to higher demands at work.

\section{Statistical analysis}

To check the data entry of the paper versions of the QWLQ-CS, 20\% of the questionnaires were tested. The analysis was performed using IBM SPSS Statistics 23. We 
assessed descriptive factors for the demographic, health-, and work-related variables. The variables were displayed for the total sample, with men and women displayed separately. Furthermore, we calculated the total score and sum scores of the subscales of the QWLQ-CS. To explore differences between groups of cancer survivors based on health- and workrelated variables, we distinguished between parametric and non-parametric tests by assessing the assumptions for normal distributions with the Kolmogorov-Smirnov test of normality and Levene's test (cutoff $p$ value $\leq 0.05$ ) [23]. In case of any violations of the assumptions, the Mann-Whitney $U$ test and the Kruskal Wallis test with post hoc tests were performed. The significance levels for these tests were $p \leq 0.05$.

\section{Results}

Of the 1613 invitations, 490 cancer survivors replied to the invitation for participation. The most commonly reported reason for non-participation was "no employment" $(N=113)$. Ultimately, a total of 302 employed or self-employed cancer survivors completed the questionnaire (Fig. 1). The sample of cancer survivors was $52 \pm 8$ years ( $28 \%$ male), mainly from Dutch origin (92\%). Cancer survivors were mostly diagnosed with breast cancer (36\%) and gynaecological cancer (17\%). The sample consisted of cancer survivors who had been diagnosed 1-3 years ago (54\%) and had most often received surgery $(39 \%)$ (Table 1$)$.

The majority of the sample had been educated to a higher professional or academic level (47\%). Most cancer survivors had a permanent employment contract (75\%), worked 12 $36 \mathrm{~h}(47 \%)$, and had worked for more than 11 years in the same job (60\%) (Table 2). The largest group worked in healthcare $(24 \%)$. The mean reported gross monthly income was between $€ 1001$ and $€ 2000$ (22\%).

\section{QWL}

The total scores for the QWLQ-CS and the subscales were calculated (Table 3 ). We found no statistically significant differences between the QWLQ-CS mean scores of men $(M=74.3)$ and women $(M=74.8)$. The mean score on the QWLQ-CS was 74.7 with a standard deviation $(S D)$ of 12.4. The subscales with the highest mean score were "Importance of work" $(M=82.5, \mathrm{SD}=14.4)$ and "Impression of the work situation" $(M=82.5, \mathrm{SD}=14.5)$. The subscale "Problems due to the health situation" had the lowest mean score $(M=48.7$, $\mathrm{SD}=26.9$ ) when scores were reversed. The subscale "Atmosphere in the work environment" had a mean score of $80.6(\mathrm{SD}=15.3)$ and "Understanding and recognition in the organisation" $75.0(\mathrm{SD}=18.7)$.

\section{Health-related variables}

Statistically significant differences between cancer survivors on QWLQ-CS scores were found based on the treatment they had received. Cancer survivors who had received chemotherapy had lower QWLQ-CS scores $(M=72.8)$ than cancer survivors who had not received this type of treatment $(M=76.5)$ $U=9095.50, p=0.003$. Furthermore, cancer survivors who had surgery $(M=75.5)$ had higher QWLQ-CS scores than cancer survivors who had not $(M=71.0) U=4813.00$, $p=0.015$. The group of cancer survivors who reported comorbidity $(M=70.7)$ had statistically significant lower QWLQ-CS scores than the group that reported no comorbidity ( $M=76.2) U=6245.50, p=0.001$ (Fig. 2).

\section{Work-related variables}

Cancer survivors with managerial positions $(M=78.6)$ had higher QWLQ-CS scores than the group without managerial positions $(M=73.4) U=6457.00, p=0.001$. Cancer survivors who worked their total contract hours had higher QWLQ-CS scores $(M=76.9)$ that statistically differed from the group who worked a proportion of their contract hours $(M=71.0)$ $U=7136.50, p=0.000$ (Fig. 3). Cancer survivors in different gross income brackets also differed statistically. The group with the lowest income $(<€ 1000)$ had lower QWLQ-CS scores $(M=74.4)$ than the group with the largest income $(>€ 4000)(M=80.0) U=753.00, p=0.012$. No statistically significant differences in QWLQ-CS scores were found between cancer survivors who reported high $(M=75.2)$ and low $(M=74.4)$ levels of mentally demanding work. However, cancer survivors who reported low level of physically demanding work had higher QWLQ-CS scores $(M=77.5)$ than the group with high levels of physically demanding work $(M=72.7) U=8487.50, p=0.001$.

\section{Discussion}

The aims of this study were as follows: (1) to describe the QWL of cancer survivors and (2) to explore associations between the QWL of cancer survivors and health- and workrelated variables. Cancer survivors had a mean score of $74.7 \pm 12.4$ on the QWLQ-CS. Cancer survivors scored low on the subscale "Problems due to the health situation" $(48.7 \pm 26.9)$. Health-related variables associated with a low QWL in cancer survivors were "Type of treatment" and "Reported co-morbidity." Furthermore, work-related variables, such as not having a managerial position, working a proportion of the contract hours, being on a low income, and having physically demanding work, were associated with a low QWL. 
Table 1 Demographics and health-related characteristics of cancer survivors

\begin{tabular}{|c|c|c|c|c|c|c|c|}
\hline & & \multicolumn{2}{|c|}{ Total } & \multicolumn{2}{|c|}{ Male } & \multicolumn{2}{|c|}{ Female } \\
\hline & & \multicolumn{2}{|c|}{$\begin{array}{l}N=302 \\
(100 \%)\end{array}$} & \multicolumn{2}{|c|}{$\begin{array}{l}N=83 \\
(28 \%)\end{array}$} & \multicolumn{2}{|c|}{$\begin{array}{l}N=219 \\
(78 \%)\end{array}$} \\
\hline \multirow[t]{2}{*}{ Age (mean in years $\pm \mathrm{SD}$ ) } & & \multicolumn{2}{|c|}{$52.4 \pm 8.1$} & \multicolumn{2}{|c|}{$54.7 \pm 8.4$} & \multicolumn{2}{|c|}{$51.6 \pm 7.9$} \\
\hline & & $N$ & $(\%)$ & $N$ & $(\%)$ & $N$ & $(\%)$ \\
\hline \multirow[t]{2}{*}{ Marital status } & $\begin{array}{l}\text { Married/(living) together } \\
\text { with a partner }\end{array}$ & 240 & (79) & 71 & $(86)$ & 169 & (77) \\
\hline & Single/divorced/widower & 62 & $(21)$ & 12 & (14) & 50 & (23) \\
\hline \multirow[t]{3}{*}{ Main wage earner } & Yes & 154 & $(51)$ & 58 & $(70)$ & 96 & (44) \\
\hline & No & 48 & (16) & 0 & $(0)$ & 48 & $(22)$ \\
\hline & Equal with partner & 97 & (32) & 25 & $(30)$ & 72 & (32) \\
\hline \multirow[t]{2}{*}{ Ethnicity } & Dutch & 279 & $(92)$ & 79 & $(95)$ & 200 & $(91)$ \\
\hline & Immigrant & 21 & (7) & 4 & (5) & 19 & (9) \\
\hline \multirow[t]{2}{*}{ Number of cancer diagnoses } & 1 diagnosis & 256 & $(85)$ & 65 & $(80)$ & 191 & $(87)$ \\
\hline & $\geq 2$ diagnoses & 45 & $(15)$ & 17 & $(20)$ & 28 & (13) \\
\hline \multirow[t]{8}{*}{ Cancer diagnoses $^{\mathrm{a}}$} & Breast cancer & 123 & (36) & 0 & $(0)$ & 123 & $(52)$ \\
\hline & Gynaecological cancer & 59 & (17) & N/A & - & 56 & (23) \\
\hline & Gastrointestinal cancer & 47 & (14) & 26 & $(28)$ & 18 & $(8)$ \\
\hline & Urological cancer & 36 & (11) & 31 & $(33)$ & 5 & (2) \\
\hline & Haematological cancer & 26 & $(8)$ & 11 & (12) & 14 & (6) \\
\hline & Head and neck cancer & 22 & $(6)$ & 17 & (18) & 5 & $(2)$ \\
\hline & Malignant melanomas & 10 & (3) & 4 & (4) & 6 & (3) \\
\hline & Others (e.g., metastases) & 17 & $(5)$ & 5 & (5) & 12 & $(5)$ \\
\hline \multirow[t]{4}{*}{ Most recent cancer diagnosis } & $<1$ year ago & 60 & $(20)$ & 13 & (16) & 47 & $(22)$ \\
\hline & 1-3 years ago & 162 & $(54)$ & 39 & $(48)$ & 123 & $(56)$ \\
\hline & 4-6 years ago & 55 & (18) & 13 & (16) & 42 & (19) \\
\hline & $>6$ years ago & 24 & (8) & 17 & $(21)$ & 7 & (3) \\
\hline \multirow[t]{5}{*}{ Cancer treatment $\mathrm{t}^{\mathrm{a}}$} & Surgery & 253 & (39) & 61 & (44) & 192 & $(38)$ \\
\hline & Radiotherapy & 152 & (23) & 30 & $(21)$ & 122 & (24) \\
\hline & Chemotherapy & 150 & (23) & 36 & (26) & 114 & (22) \\
\hline & Hormone therapy & 67 & (10) & 3 & (2) & 64 & (13) \\
\hline & Other $^{\mathrm{b}}$ & 31 & $(5)$ & 10 & (7) & 21 & (4) \\
\hline Currently treated & Yes & 42 & (14) & 7 & (8) & 35 & (16) \\
\hline \multirow[t]{4}{*}{ Last cancer treatment } & $<1$ year ago & 101 & (33) & 26 & $(31)$ & 75 & (34) \\
\hline & 1-3 years ago & 96 & (32) & 23 & (28) & 73 & (33) \\
\hline & 4-6 years ago & 41 & (14) & 10 & (12) & 31 & (14) \\
\hline & $>6$ years ago & 21 & (7) & 16 & (19) & 5 & (2) \\
\hline Co-morbidity & Yes & 76 & $(25)$ & 20 & (24) & 56 & (26) \\
\hline
\end{tabular}

N/A not applicable

${ }^{\text {a }}$ Percentages equal total diagnoses/treatments

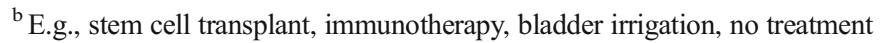

\section{QWL}

This study provides new insights into the QWL of cancer survivors. No gender differences in QWL were found, which was unexpected as research suggests that female gender may have a negative impact on employment [10,24]. Perhaps, the composition of our sample explains the similar QWL scores between genders. More cancer survivors were diagnosed $>1$ year ago, but may be factors that affect employment and QWL of females negatively only exist shortly after cancer diagnosis, and do not persist over time. For instance, male cancer survivors more often indicated a cancer diagnoses as minimal impact on their lives in comparison to women [25]. But may be after a year, this impact also decreased for women 
Table 2 Work characteristics of cancer survivors

\begin{tabular}{|c|c|c|c|c|c|c|c|}
\hline & & \multicolumn{2}{|c|}{ Total } & \multicolumn{2}{|c|}{ Male } & \multicolumn{2}{|c|}{ Female } \\
\hline & & \multicolumn{2}{|c|}{$\begin{array}{l}N=302 \\
(100 \%)\end{array}$} & \multicolumn{2}{|c|}{$\begin{array}{l}N=83 \\
(28 \%)\end{array}$} & \multicolumn{2}{|c|}{$\begin{array}{l}N=219 \\
(78 \%)\end{array}$} \\
\hline & & $N$ & $(\%)$ & $N$ & $(\%)$ & $N$ & $(\%)$ \\
\hline \multirow[t]{3}{*}{ Education } & Primary/secondary education & 55 & $(18)$ & 18 & $(22)$ & 37 & (17) \\
\hline & Intermediate vocational education & 102 & (34) & 27 & $(33)$ & 72 & (33) \\
\hline & Higher prof/academic education & 143 & $(47)$ & 35 & $(42)$ & 103 & $(47)$ \\
\hline \multirow[t]{3}{*}{ Work contract } & Permanent employment & 225 & (75) & 66 & $(80)$ & 159 & (73) \\
\hline & Temporary employment & 19 & $(6)$ & 2 & (2) & 17 & $(8)$ \\
\hline & Self-employed & 44 & $(15)$ & 10 & $(12)$ & 34 & $(16)$ \\
\hline \multirow[t]{3}{*}{ Contract hours } & $<12 \mathrm{~h}$ & 12 & (4) & 0 & $(0)$ & 12 & $(6)$ \\
\hline & $12-36 \mathrm{~h}$ & 141 & $(47)$ & 16 & (19) & 125 & $(57)$ \\
\hline & $>36 \mathrm{~h}$ & 112 & (37) & 59 & $(71)$ & 53 & (24) \\
\hline \multirow[t]{4}{*}{ Years in the job } & $0-3$ years & 36 & (12) & 6 & (7) & 30 & (14) \\
\hline & $3-7$ years & 40 & (13) & 8 & $(10)$ & 32 & $(15)$ \\
\hline & $7-11$ years & 43 & (14) & 12 & $(15)$ & 31 & (14) \\
\hline & $>11$ years & 182 & $(60)$ & 56 & $(68)$ & 126 & $(58)$ \\
\hline Managerial position & Yes & 78 & (26) & 33 & $(40)$ & 45 & $(21)$ \\
\hline \multirow[t]{9}{*}{ Occupational sector } & Health care and pharmacy & 73 & (24) & 7 & $(8)$ & 66 & $(30)$ \\
\hline & Educational & 34 & (11) & 4 & $(5)$ & 30 & (14) \\
\hline & Government & 30 & (10) & 8 & (10) & 22 & $(10)$ \\
\hline & Industrial/production & 20 & (7) & 12 & (14) & 8 & (4) \\
\hline & Facility management & 12 & (4) & 4 & (5) & 8 & $(4)$ \\
\hline & Wholesale/retail business & 15 & (5) & 2 & (2) & 13 & $(6)$ \\
\hline & Transport/logistics & 16 & (5) & 9 & (11) & 7 & (3) \\
\hline & Business services & 26 & (9) & 10 & (12) & 16 & $(7)$ \\
\hline & Other & 75 & (25) & 26 & $(31)$ & 49 & (22) \\
\hline \multirow[t]{5}{*}{ Gross income } & $\leq € 1000$ & 46 & (15) & 6 & (7) & 40 & (18) \\
\hline & $€ 1001-€ 2000$ & 65 & (22) & 6 & (7) & 59 & (27) \\
\hline & $€ 2001-€ 3000$ & 60 & $(20)$ & 19 & (23) & 41 & (19) \\
\hline & $€ 3001-€ 4000$ & 51 & (17) & 13 & (16) & 38 & (17) \\
\hline & $\geq € 4000$ & 47 & (16) & 28 & (34) & 19 & (9) \\
\hline
\end{tabular}

and, therefore, does not create gender differences in QWL. To verify this hypothesis, QWL should be evaluated among only recent diagnosed cancer survivors.
We did not found differences in QWL between cancer survivors who were recently returned to work or longer ago. This was unexpected, as the latter group is diagnosed longer ago
Table 3 Sum scores of subscales and total score QWLQ-CS $(0$ 100)

\begin{tabular}{|c|c|c|c|c|c|c|}
\hline \multicolumn{2}{|c|}{ Subscale } & \multirow{2}{*}{$\begin{array}{l}\begin{array}{l}\# \text { of } \\
\text { items }\end{array} \\
4\end{array}$} & \multirow{2}{*}{$\begin{array}{l}N \\
302\end{array}$} & \multirow{2}{*}{$\begin{array}{l}\text { Mean } \pm S D \\
83 \pm 14\end{array}$} & \multirow{2}{*}{$\begin{array}{l}\text { Median } \\
80\end{array}$} & \multirow{2}{*}{$\begin{array}{l}\text { Range } \\
25-100\end{array}$} \\
\hline 1 & Importance of work & & & & & \\
\hline 2 & Impression of the work situation & 5 & 301 & $83 \pm 15$ & 84 & $24-100$ \\
\hline 3 & Atmosphere in the work environment & 5 & 291 & $81 \pm 15$ & 80 & $8-100$ \\
\hline 4 & $\begin{array}{l}\text { Understanding and recognition in the } \\
\text { organization }\end{array}$ & 5 & 264 & $75 \pm 19$ & 80 & $0-100$ \\
\hline \multirow[t]{2}{*}{5} & Problems due to the health situation & 4 & 294 & $49 \pm 27$ & 45 & $0-100$ \\
\hline & Total score QWLQ-CS & 23 & $301 *$ & $75 \pm 12$ & 76 & $30-100$ \\
\hline
\end{tabular}

${ }^{\text {a }}$ One cancer survivor had completed $<50 \%$ of the items; therefore, it was not possible to calculate the overall score 


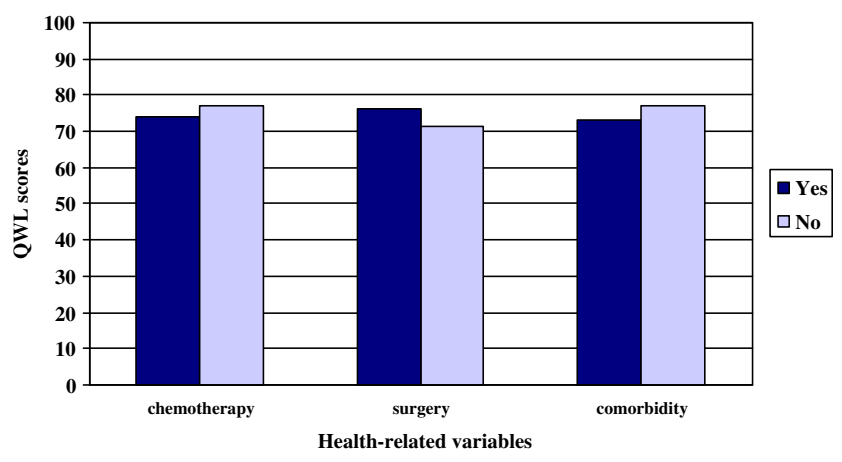

Fig. 2 Statistically significant differences $(p \leq 0.05)$ in QWLQ-CS scores between cancer survivors based on health-related variables

and consequently would have fewer health complaints and higher QWL. A possible explanation is a "healthy worker effect" [26], which implicates that cancer survivors who recently returned to work and participated in this study, might have fewer physical and mental limitations because they are still able to perform work activities. Therefore, we did not found differences in QWL between them and cancer survivors who returned to work longer ago.

The subscale "Problems due to the health situation" had the lowest score, which indicates that the health of cancer survivors has negative impact on their QWL. For instance, the items in this subscale were about experiencing fatigue, limitations due to the health situation, having little trust in one's body, and uncertainty about the future. The low scores on this subscale emphasized the health problems that cancer survivors experience in work situations. However, when assessing the content of these items, the health-related problems might also be relevant for employees with other chronic diseases. For instance, fatigue is indicated as one of the most unpleasant problems among patients with rheumatoid arthritis [27], and uncertainty about the future is also experienced by patients with multiple sclerosis (MS) [28]. Workers with a chronic health condition (e.g., musculoskeletal conditions) also experienced employment difficulties, such as reduced work ability [29]. Therefore, the QWLQ-CS might be used more widely to support employees with chronic physical diseases (e.g., cancer, rheumatoid arthritis, or MS) during return-towork or work continuation processes.

The standard deviation (SD) of the subscale "Problems due to the health situation" was large (26.9), which indicates great differences in subscale scores between cancer survivors. This might be explained by the differences between cancer survivors in types of cancer and treatments, who had been diagnosed recently or longer ago. For instance, male cancer survivors who are treated for prostate cancer often undergo local anaesthesia [30], while the most common treatments for breast cancer include surgery, radiation treatment, chemotherapy, and hormonal therapy [31]. Cancer survivors in this sample were therefore experiencing different physical and psychological consequences at the time of this study, which could explain the large variation of responses on the items about fatigue, limitations, little trust in own body, and uncertainty about the future.
Fig. 3 Statistically significant differences $(p \leq 0.05)$ in QWL between cancer survivors based on work-related variables

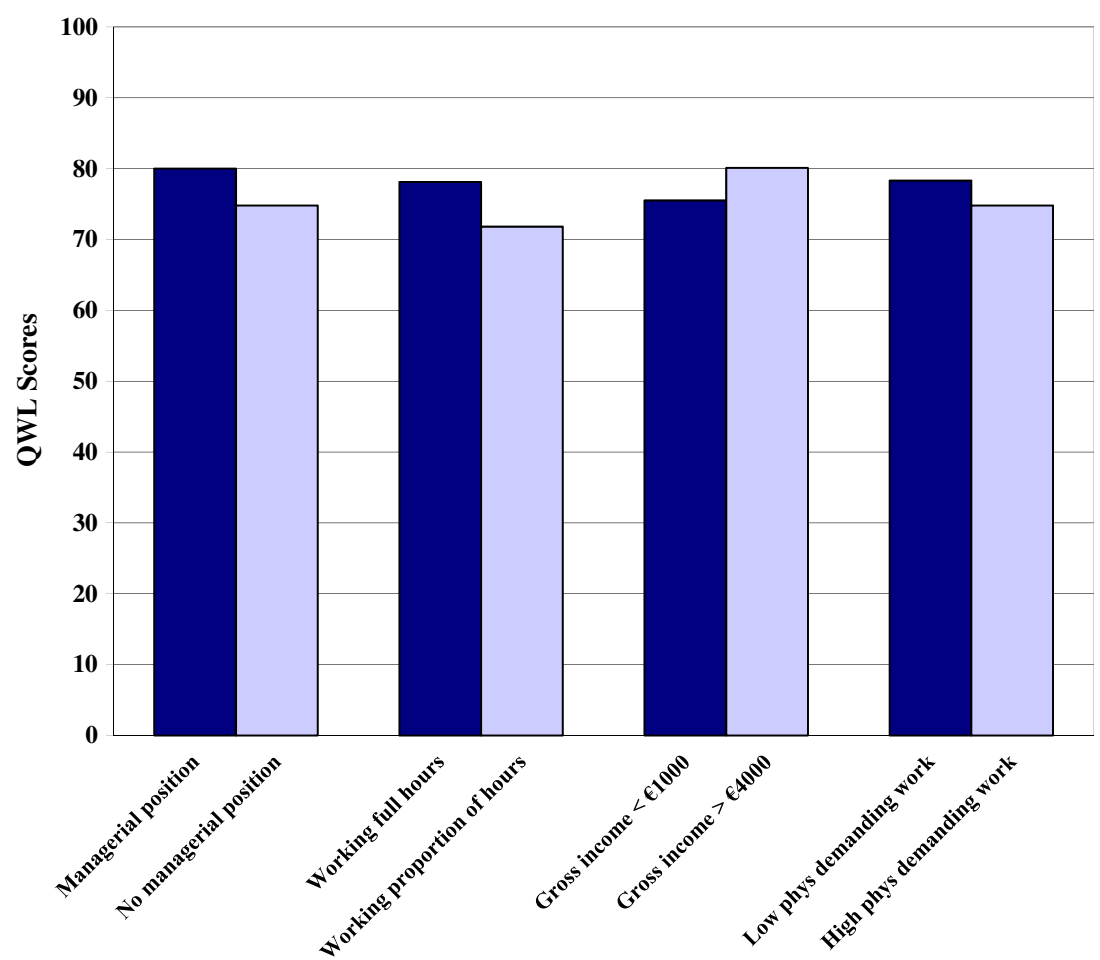

Work-related variables 
In this study, we found that low QWL in cancer survivors was associated with type of treatment and reported co-morbidity. The findings regarding chemotherapy are consistent with previous research; a systematic literature review found strong evidence that chemotherapy was a prognostic factor for return-to-work [32]. Furthermore, chemotherapy at the time of diagnosis was also found to be independently associated with unemployment 4 years after the diagnosis [33]. The relation between co-morbidity and employment was found among employees with chronic diseases as well; co-morbidity was associated with worse return-to-work outcomes in workers with musculoskeletal injuries [34]. Cancer survivors who had surgery had higher QWLQ-CS scores. Most likely, this is a consequence of receiving no additional treatments when the tumour has been operatively removed [35].

In this study, work-related variables were found to be associated with a low QWLQ-CS score. Some of these findings were in line with previous research while others were not. For instance, the association between having a managerial function and QWL was not found by previous studies. However, previous research did find that some characteristics of a managerial function, such as job autonomy, were previously related to QWL among nurses [36], and also, a higher autonomy reduced the risk of loss of paid employment among workers with health problems [37], suggesting an indirect relation to QWL. Also, the factor flexible arrangement, another potential characteristic of a managerial function, has been associated with a greater likelihood of being employed or returning to work among cancer survivors [11]. Furthermore, no previous literature examined the relationship between working a proportion of contract hours and QWL, but most likely, the cancer survivors that have not fully returned to work are recently diagnosed and treated which affects their work ability [38] and consequently QWL negatively. Next, low income was found to be associated with low QWL which is consistent with the finding that low income is related to more employment issues. For instance, previous research also identified having a low income a barrier to returning to work [10]. Physically demanding work was associated to low QWLQ-CS scores, and this outcome is consistent with previous findings. For instance, manual labour is negatively associated with return-to-work [39]. Unexpected, mentally demanding work was not associated with low QWLQCS scores. Previous research described cancer survivors who reported significantly poorer mental work capacity than controls [40]. Therefore, we expected to find a lower QWLQ-CS score among cancer survivors with mentally demanding work. However, earlier research indicated that stress can be associated with positive work experiences due to the multiple dimensions of the phenomenon stress [41]. It is possible that cancer survivors with mentally demanding jobs do not experience this as a negative consequence.

\section{Strengths and limitations}

One strength of this study was the representative sample of Dutch cancer survivors with regard to the distribution between men and women. Between the ages of 25 and 55, more cancer survivors are female [42], because breast cancer and gynaecological cancer are more common in this group. More specifically, the 5-year prevalence of cancer survivors in the Netherlands between the ages of 15 and 59 was 32.235 for men and 59.795 for women in 2015 [42]. According to these numbers, the ratio of cancer in men to women is $1: 2$. The same trend is visible in our sample; the ratio was 1:2.5. Although a large part of the sample was diagnosed with cancer between 1 and 3 years ago, we were also able to include cancer survivors who were recently diagnosed with cancer $(<1$ year ago) and who were still receiving treatment. Our description of QWL in this article is therefore illustrative of cancer survivors who are in the process of returning to work and for cancer survivors who returned to work longer ago. This enables us to draw conclusions for both groups of cancer survivors. Unfortunately, our sample does not cover a diverse range of ethnic backgrounds; we did not anticipate that our recruitment strategies would target only Dutch natives. Research in the Netherlands indicates that immigrant women experience cancer as culturally taboo, which makes them reluctant to discuss their illness openly [43]. It is thus possible that cancer survivors with immigrant backgrounds were invited to participate but chose not to respond. This implicates that the results of this study cannot be generalized to cancer survivors of all ethnicities.

\section{Implications for future research}

We found statistically significant differences in QWLQ-CS scores related to health- and work-related variables. However, due to the cross-sectional design of this study, we were unable to make predictions about risk factors for low QWL. Future research may determine prognostic factors of QWL in order to develop tailored interventions of cancer survivors who are at risk for low QWL. For instance, an intervention for cancer survivors in physical demanding jobs might focus on more breaks and tools to diminish the physical workload. We also suggest focusing on work-life trajectories of cancer survivors in order to study possible effects on QWL, for instance, to study differences between cancer survivors who did not work for extended periods of time and cancer survivors who recently returned to work. Furthermore, to extend the applicability of the QWLQ-CS, we suggest to assess its validity and reproducibility among employed people with 
other chronic diseases as well people with chronic diseases other than cancer may also experience work-related difficulties [44]. If the QWLQ-CS proves to be valid and reproducible, the same recommendations regarding cancer survivors could be made for employees with other chronic physical diseases. Furthermore, it would be possible to compare QWL between employees with different chronic diseases and describe their work situation.

\section{Implications for practice}

The QWLQ-CS needs more research to increase its usability in practice. However, the results of this study may increase awareness among actors in the occupational healthcare (e.g., occupational physicians, general physicians, nurses, human resource departments) about the associations between QWL and health- and work-related variables. This insight may help them identifying groups of cancer survivors with similar health- and work-related variables, who might experience low QWL and are in need of more attention. For instance, actors who support cancer survivors with co-morbidity should be aware of the relationship between co-morbidity and QWL and, as a possible consequence, less successful work continuation. However, healthcare actors are only part of the process; self-management is important for cancer survivors as a means of enabling and empowering themselves [45]. If cancer survivors had more knowledge about the reintegration process and the relation between QWL and health- and work-related variables, they would be able to request support and adjustments when necessary.

\section{Conclusion}

This study described the QWL of cancer survivors and associations between QWL and health- and work-related variables. Based on these variables, it is possible to indicate groups of cancer survivors who need more attention and support regarding QWL and work continuation.

Acknowledgments We would like to thank our research assistant, S. van Hezel, for her help in the data collection. We are grateful to the Dutch online cancer platform "Kanker.nl" and the Dutch cancer patient organization "Hoofd-Hals" for their help in recruiting cancer survivors. This work was supported by COST Action IS1211 CANWON (A.G.E.M. de Boer, S.J. Tamminga, and M. de Jong).

Compliance with ethical standards Ethical approval was deemed unnecessary by the Medical Ethics Committee of the Academic Medical Center (W14 218\#14.17.0264)

Funding The study forms part of the research project "Quality of working life of cancer survivors" and was funded with a grant from the Dutch Cancer Society, registration number 2011-5228.

\section{Conflict of interest None}

Informed consent Informed consent was obtained from all individual participants included in the study.

Open Access This article is distributed under the terms of the Creative Commons Attribution-NonCommercial 4.0 International License (http:/ creativecommons.org/licenses/by-nc/4.0/), which permits any noncommercial use, distribution, and reproduction in any medium, provided you give appropriate credit to the original author(s) and the source, provide a link to the Creative Commons license, and indicate if changes were made.

\section{References}

1. Ferlay J, Soerjomataram I, Ervik M, Dikshit R, Eser S, Mathers C, Rebelo M, Parkin DM, Forman D, Bray F (2013) GLOBOCAN 2012 v1.0, Cancer Incidence and Mortality Worldwide: IARC CancerBase No. 11 [Internet]. International Agency for Research on Cancer. http://globocan.iarc.fr. Accessed 25 April 2016

2. Hoffman B (2005) Cancer survivors at work: a generation of progress. CA Cancer J Clin 55(5):271-280

3. Miller KD, Siegel RL, Lin CC, Mariotto AB, Kramer JL, Rowland JH, Stein KD, Alteri R, Jemal A (2016) Cancer treatment and survivorship statistics, 2016. CA Cancer J Clin. doi:10.3322 caac. 21349

4. Schultz IZ, Gatchel RJ (2015) Handbook of return to work: from research to practice, vol 1 . Springer, US

5. Kennedy F, Haslam C, Munir F, Pryce J (2007) Returning to work following cancer: a qualitative exploratory study into the experience of returning to work following cancer. Eur J Cancer Care 16(1):17-25

6. Petersson LM, Nilsson MI, Alexanderson K, Olsson M, WennmanLarsen A (2013) How do women value work shortly after breast cancer surgery and are their valuations associated with being on sick leave? J Occup Rehabil 23(3):391-399

7. Mehnert A, Koch U (2013) Work satisfaction and quality of life in cancer survivors in the first year after oncological rehabilitation. Work 46(4):407-415

8. de Boer AG, Taskila T, Ojajarvi A, van Dijk FJ, Verbeek JH (2009) Cancer survivors and unemployment: a meta-analysis and metaregression. JAMA 301(7):753-762

9. Tamminga SJ, Bultmann U, Husson O, Kuijpens JL, Frings-Dresen MH, de Boer AG (2016) Employment and insurance outcomes and factors associated with employment among long-term thyroid cancer survivors: a population-based study from the PROFILES registry. Qual Life Res 25(4):997-1005

10. Mehnert A (2011) Employment and work-related issues in cancer survivors. Crit Rev Oncol Hematol 77(2):109-130

11. Mehnert A, de Boer A, Feuerstein M (2013) Employment challenges for cancer survivors. Cancer 119(S11):2151-2159

12. Taskila T, Lindbohm ML (2007) Factors affecting cancer survivors' employment and work ability. Acta Oncol 46(4):446-451

13. Neumark D, Bradley CJ, Henry M, Dahman B (2015) Work continuation while treated for breast cancer: the role of workplace accommodations. ILR Review 68(4):916-954

14. Lee YW, Dai YT, Park CG, McCreary LL (2013) Predicting quality of work life on nurses' intention to leave. J Nurs Scholarsh 45(2): $160-168$

15. de Wind A, Geuskens GA, Ybema JF, Blatter BM, Burdorf A, Bongers PM, van der Beek AJ (2014) Health, job characteristics, 
skills, and social and financial factors in relation to early retirement-results from a longitudinal study in the Netherlands. Scand J Work Environ Health 40(2):186-194

16. Tamminga S, de Boer A, Verbeek J, Frings-Dresen M (2010) Return-to-work interventions integrated into cancer care: a systematic review. Occup Environ Med 67(9):639-648

17. de Boer AG, Taskila TK, Tamminga SJ, Feuerstein M, FringsDresen MH, Verbeek JH (2015) Interventions to enhance returnto-work for cancer patients. The Cochrane database of systematic reviews (9):Cd007569. doi:10.1002/14651858

18. Wells M, Williams B, Firnigl D, Lang H, Coyle J, Kroll T, MacGillivray S (2013) Supporting 'work-related goals' rather than 'return to work' after cancer? A systematic review and meta-synthesis of 25 qualitative studies. Psychooncology 22(6):1208-1219

19. von Elm E, Altman DG, Egger M, Pocock SJ, Gotzsche PC, Vandenbroucke JP (2014) The Strengthening the Reporting of Observational Studies in Epidemiology (STROBE) Statement: guidelines for reporting observational studies. Int J Surg 12(12): 1495-1499

20. de Jong M, Tamminga SJ, de Boer AG, Frings-Dresen MH (2016) Quality of working life of cancer survivors: development of a cancer-specific questionnaire. J Cancer Surviv 10(2):394-405

21. de Jong M, Tamminga SJ, de Boer AG, Frings-Dresen MH (2016) The quality of working life questionnaire for cancer survivors (QWLQ-CS): a pre-test study. BMC Health Serv Res 16(1):194

22. van Veldhoven M, Meijman T (1994) Questionnaire perception and judgement of work [in Dutch: vragenlijst beleving en beoordeling van de arbeid]. NIA, Amsterdam

23. Field A (2009) Discovering statistics using SPSS. Sage publications Ltd, London

24. Bradley CJ, Bednarek HL (2002) Employment patterns of longterm cancer survivors. Psychooncology 11(3):188-198

25. Foley KL, Farmer DF, Petronis VM, Smith RG, McGraw S, Smith K, Carver CS, Avis N (2006) A qualitative exploration of the cancer experience among long-term survivors: comparisons by cancer type, ethnicity, gender, and age. Psychooncology 15(3):248-258

26. Buckley JP, Keil AP, McGrath LJ, Edwards JK (2015) Evolving methods for inference in the presence of healthy worker survivor bias. Epidemiol 26(2):204-212

27. Singh H, Arya S, Talapatra P, Lather K, Mathur R, Singhania A, Chaudhary V (2014) Assessment of fatigue in rheumatoid arthritis (by functional assessment of chronic illness therapy-fatigue score) and its relation to disease activity and anemia. J Clin Rheumatol 20(2):87-90

28. Davies F, Edwards A, Brain K, Edwards M, Jones R, Wallbank R, Robertson NP, Wood F (2015) 'You are just left to get on with it': qualitative study of patient and carer experiences of the transition to secondary progressive multiple sclerosis. BMJ Open 5(7):e007674

29. Koolhaas W, van der Klink JJL, de Boer MR, Groothoff JW, Brouwer S (2014) Chronic health conditions and work ability in the ageing workforce: the impact of work conditions, psychosocial factors and perceived health. Int Arch Occup Environ Health 87(4): 433-443

30. Heidenreich A, Bastian PJ, Bellmunt J, Bolla M, Joniau S, van der Kwast T, Mason M, Matveev V, Wiegel T, Zattoni F, Mottet N (2014) EAU guidelines on prostate cancer. Part 1: screening, diagnosis, and local treatment with curative intent - update 2013. Eur Urol 65(1):124-137
31. Schmitz KH, Speck RM, Rye SA, DiSipio T, Hayes SC (2012) Prevalence of breast cancer treatment sequelae over 6 years of follow-up. Cancer 118(S8):2217-2225

32. van Muijen P, Weevers NLEC, Snels IAK, Duijts SFA, Bruinvels DJ, Schellart AJM, van der Beek AJ (2013) Predictors of return to work and employment in cancer survivors: a systematic review. Eur J Cancer Care 22(2):144-160

33. Jagsi R, Hawley ST, Abrahamse P, Li Y, Janz NK, Griggs JJ, Bradley C, Graff JJ, Hamilton A, Katz SJ (2014) Impact of adjuvant chemotherapy on long-term employment of survivors of early-stage breast cancer. Cancer 120(12):1854-1862

34. Boot CRL, Hogg-Johnson S, Bültmann U, Amick BC, van der Beek AJ (2014) Differences in predictors for return to work following musculoskeletal injury between workers with and without somatic comorbidities. Int Arch Occup Environ Health 87(8):871-879

35. Kandioler D, Krömer E, Tüchler H, End A, Müller MR, Wolner E, Eckersberger F (1998) Long-term results after repeated surgical removal of pulmonary metastases. Ann Thorac Surg 65(4):909-912

36. Hsu MY, Kernohan G (2006) Dimensions of hospital nurses' quality of working life. J Adv Nurs 54(1):120-131

37. Leijten FRM, de Wind A, van den Heuvel SG, Ybema JF, van der Beek AJ, Robroek SJW, Burdorf A (2015) The influence of chronic health problems and work-related factors on loss of paid employment among older workers. J Epidemiol Commun Health 69(11): $1058-1065$

38. Pryce J, Munir F, Haslam C (2007) Cancer survivorship and work: symptoms, supervisor response, co-worker disclosure and work adjustment. J Occup Rehabil 17(1):83-92

39. Spelten ER, Sprangers MA, Verbeek JH (2002) Factors reported to influence the return to work of cancer survivors: a literature review. Psychooncology 11(2):124-131

40. Gudbergsson SB, Fosså SD, Borgeraas E, Dahl AA (2006) A comparative study of living conditions in cancer patients who have returned to work after curative treatment. Support Care Cancer 14(10):1020-1029

41. Boswell WR, Olson-Buchanan JB, LePine MA (2004) Relations between stress and work outcomes: the role of felt challenge, job control, and psychological strain. J Vocat Behav 64(1):165-181

42. Numbers about cancer [In Dutch: Cijfers over kanker]. (2016) Netherlands Comprehensive Cancer Organisation [in Dutch: Integraal Kankercentrum Nederland (IKNL)]. http://www. cijfersoverkanker.nl/leeftijd-geslacht-54.html. Accessed 26 June 2016

43. de Kruif A, Derks M, de Boer M, Winkels R, Visser M, Kampman E, Westerman M (2016) Abstract P1-10-28: Cultural and religious differences during breast cancer treatment between Dutch and nonWestern immigrant women. Paper presented at the Thirty-Eighth Annual CTRC-AACR San Antonio Breast Cancer Symposium, San Antonio, TX

44. Detaille SI, Heerkens YF, Engels JA, van der Gulden JWJ, van Dijk FJH (2009) Common prognostic factors of work disability among employees with a chronic somatic disease: a systematic review of cohort studies. Scand J Work Environ Health 35:261-281

45. McCorkle R, Ercolano E, Lazenby M, Schulman-Green D, Schilling LS, Lorig K, Wagner EH (2011) Self-management: enabling and empowering patients living with cancer as a chronic illness. CA Cancer J Clin 61(1):50-62 